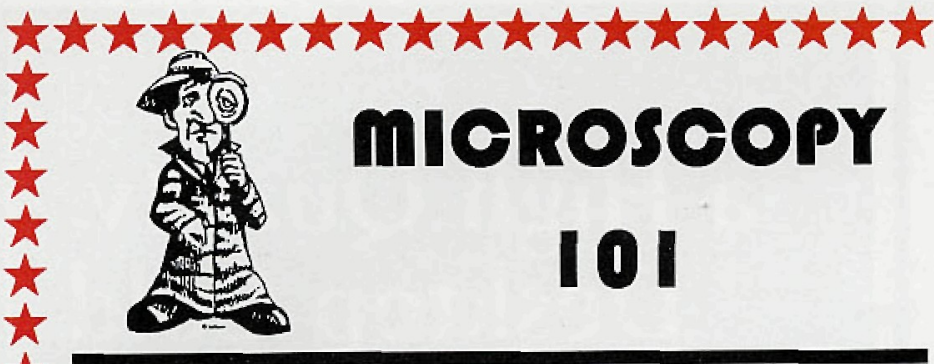

We appreciate the response to this publication feature - and welcome all contributions. Contributions may be sent to Phil Oshel, our Technical Editor at:

Mr. Phil Oshel

Station A

PO Box 5037

Champaign IL 61825-5037

or by eMail: poshel@hotmail.com

Please note new eMail address

\section{A Protocol for Immunostaining of Microtubules and Microfilaments in the Secondary Vascular Tissues of Hardwood Trees for Fluorescence Microscopy}

The plant cytoskeleton has been much studied in single cells and primary growth systems. Technical problems have meant that the secondary vascular tissues of trees has been largely Ignored. However, the procedure below, combined with the advice on sampling in the previous article "Big is Beautiful" in the November issue (\#97-9) of this publication should permit others to explore this fascinating developmental system.

1) Prefix in $100 \mu \mathrm{M}$ MRS (3-maleimidobenzoic acid $\mathrm{N}$ hydroxysuccinimide ester) for ca. 1.5 hours

2) Fix in $3.7 \%$ freshly-made $p$-formaldehyde in $12.5 \mathrm{mM}$ Plperazine-N,N'-bis[2-ethanesulphonic acid], pH 6.9, (PIPES buffer) for ca. 3 hours

3) Trim to final block size, and store, in PIPES buffer overnight (ca. $15-20$ hours)

4) Dehydrate in ethanol, 30 minutes each at $30,50,7080,90 \%$ and $2 \times 30$ minutes in $100 \%$. To last $100 \%$ step, add equal volume of BMM resin (4 parts of n-butyl methacrylate: 1 part methyl methacrylate, with $5 \mathrm{mM}$ dithiothreito), leave overnight

5) Replace half volume in vial with pure BMM resin, leave for ca. 9 hours

6) Replace all volume with pure BMM resin and leave overnight

7) Replace all volume with pure BMM resin and leave for ca.. 5.5 hours

NB: All above steps 1-7 performed at room temperature on rotator in stoppered glass vials

8) Replace all volume with BMM resin \& $0.5 \%$ benzoin methyl ether, leave in dark at ca. $+5^{\circ} \mathrm{C}$, rotating, for ca. 7 hours

9) Embed in nearly full, stoppered polypropylene capsules, cure overnight with long wavelength ultraviolet light at $-20^{\circ} \mathrm{C}$

10) Cut sections dry with glass knives at $6-10 \mu \mathrm{m}$, transfer to a drop of water on albumen-coated multiwell glass slides

11) Dry down overnight at ca. $40^{\circ} \mathrm{C}$

12) Process for cytoskeleton staining of a-tubulin (for microtubules) and $F$-actin (for microfilaments):

a) ca. 10 minutes in acetone (with minimal agitation) to remove b) wash $2 \times 2$ minutes in PBS $\left(\mathrm{NaCl}, 8 \mathrm{~g} ; \mathrm{KCl}, 0.2 \mathrm{~g} ; \mathrm{Na}_{2} \mathrm{HPO}_{4}, 1.15 \mathrm{~g}\right.$ $\mathrm{KH}_{2} \mathrm{PO}_{4}, 0.2 \mathrm{~g} ; \mathrm{NaN}_{3}, 0.2 \mathrm{~g}$ per l; pH 7.3-7.6)

c) block (in solution of $6 \% \mathrm{BSA} ; 0.1 \%$ fish skin gelatin; $5 \%$ goat serum; $0.05 \mathrm{M}$ glycine in PBS), for ca. 45 minutes

d) primary antibody $(20 \mu \mathrm{l}$ mouse-anti-a-tubulin (Amersham) $+200 \mu \mathrm{l}$ PBS) or ( $2 \mu \mathrm{l}$ mouse-anti-F-actin (ICN) $+200 \mu \mathrm{l}$ PBS), for ca. 2 hours

e) wash $3 \times 5$ minutes in PBS

f) secondary antibody [20 $\mu$ / FITC-labeled anti-mouse (Sigma) $+600 \mu l$ solution of $1 \%$ BSA and $0.1 \%$ fish skin gelatin in PBS], for ca. 1 hour

g) wash $3 \times 5$ minutes in PBS

h) stain sections in $0.01 \%$ toluidine blue till light blue, rinse in PBS

NB: all above steps ah performed at room temperature: steps $c, d$ and $f$ carried out in sealed plastic box with humid environment

i) mount in Vectashield ${ }^{\mathrm{TM}}$ (Vector Laboratories, Peterborough, UK), apply coverslip, store in refrigerator overnight, view next day with appropriate filter combinations.

Nigel Chaffey,

Swedish University of Agricultural Sciences, Umeá, Sweden

\section{Making Silianted Slides for Mounting Sections}

We have found the following very useful over the years. I can not take credit, however, as the method originally came from $\mathrm{G}$. Farmillo, a technical specialist at Dimension Laboratories, Canada (unpublished).

Silanated Slides

(Aptex: 3-aminopropyltriethoxysilane from Sigma)

1. Wash slides in detergent.

2. Rinse in running tapwater $10-15$ minutes.

3. Rinse in distilled water.

4. Rinse in acetone 5 minutes.

5. Coat in $2 \%(V / N)$ Aptex in acetone 5 minutes.

6. Rinse in luke-warm running tap water 2 minutes.

7. Rinse in distilled water.

8. Air or oven dry at $40^{\circ} \mathrm{C}$ in a dust-free area.

9. Wrap, and store at room temperature up to 1 month, or at $-20^{\circ} \mathrm{C}$ for several months. Freshly coated slides are best.

\section{Dr. Sharon Miksys, University of Toronto}

Further information about this method comes from Cohn Henderson. who gives another time schedule, and writes:

"Ultimate" credit for the following belongs to Weetall who published his concept in both Nature and Science (1969), that enzymes (proteins) could be bound to a silica (glass) surface using AAS.

I expect that there may be earlier sources for this idea.

Rentrope et al. did report the use of AAS for insitu hybridization (Histochem J 18:271-276,1986), and Maddox reported on the application of AAS to routine histology ( $\mathrm{J}$ ClinPathol 40:1256-1257).

I only developed and reported on a very much shortened procedure for silanizing slides ( $40 \mathrm{sec}$. as opposed to 2 days; 10 seconds in silane, and three 10 second deionized water rinses) and its application to routine histotechnology. At the time I was unaware of the Maddox reference; it was the referees which directed me to his work.

Henderson, C. 1989. Aminoalkylsilane: an inexpensive, simple preparation for slide adhesion. Joumal of Histotechnology 12(2):123-124.

Cohn Henderson

St. Joseph's Health Centre, London, ON, Canada resin 